\title{
Improved edge strength in a facial prosthesis by incorporation of tulle: A clinical report
}

\author{
B. Karayazgan, DDS, ${ }^{a}$ Y. Gunay, DDS, MS, ${ }^{\text {b }}$ and G. Evlioğlu, DDS, MS \\ School of Dentistry, Istanbul University, and GATA Military Training Hospital, Istanbul, Turkey \\ This clinical report describes the use of tulle for increasing the tear resistance of a facial prosthesis. By \\ incorporating tulle, a prosthesis' margins may be more stable, more resistant to tearing, and less likely \\ to deform while adhesive, cosmetics, and cleaning agents are applied and removed. (J Prosthet Dent \\ 2003;90:526-9.)
}

$\mathrm{R}$

estoration of a mid-facial defect is a challenge for the maxillofacial prosthodontist and surgeon. The surgical limitations for treating these complex defects include compromised tissue because of radiation therapy, the need for the defect to be observed periodically for recurrence, and the physical condition of the patient. The prosthodontist is limited by the materials used for fabrication of a facial prosthesis, movable tissue beds, graft and flap applications, unsuitability of anatomic undercuts, and patient acceptance toward the use of a prosthesis. ${ }^{1}$ The aim of a facial prosthesis is to fulfill the esthetic needs of the patient and to improve the patient's quality of life. It is important that the patient be informed regarding the esthetics that may be achieved with prosthesis and of the limitations of the materials currently used to fabricate maxillofacial prostheses because they are not yet ideal for simulating natural skin. Human skin is a multilayered structure. Each layer differs in thickness, histologic components, and pigments. Conditions such as perspiration, temperature, and ultraviolet light affect the color and reflective properties of skin. ${ }^{1}$ If the patient's expectations and limitations of the prosthesis are not clearly defined, it is likely that both the prosthodontist and the patient will be disappointed once the prosthesis is completed. ${ }^{1,2}$

The success of any facial prosthesis depends on the physical and mechanical properties of the material used in its fabrication. ${ }^{3}$ Although there are many materials available for the fabrication of a facial prosthesis, none fulfills all the requirements for a satisfactory prosthesis. ${ }^{1}$

Discoloration and loss of mechanical and physical properties occur over time. Most degradation occurs at the margins. ${ }^{1-5}$ The margins are particularly susceptible to degradation because of poor tear resistance. As a result of the use of colorants, adhesives, cosmetic agents,

Presented at the 50th annual meeting of the American Academy of Maxillofacial Prosthetics. November 2002, Orlando, Fla.

a Resident, Department of Maxillofacial Prosthodontics, School of Dentistry, Istanbul University.

${ }^{\mathrm{b}}$ Assistant Professor, Department of Prosthetics, GATA Military Training Hospital, Dental Clinic.

cAssistant Professor, Department of Maxillofacial Prosthodontics, School of Dentistry, Istanbul University. solvents, and cleaners that are applied to the prosthesis, marginal breakdown occurs. ${ }^{6-10}$ The clinical life of adhesive-retained facial prosthesis averages about 6 months to 1 year before replacement is needed. ${ }^{11,1} \mathrm{Fa}$ cial prostheses require frequent replacement because the elastomer and its coloring agents undergo changes. ${ }^{4,5,11,12}$ Degradation of the color or physical properties of the prosthesis are the principle reasons for replacement. Various reinforcements have been evaluated to assess their effect on the mechanical properties of a particular silicone elastomer used for preparation of a facial composition. ${ }^{13,14}$ The use of fibril or silica reinforcements has been investigated. ${ }^{14-17}$ In a study of maxillofacial elastomers reinforced with silica powder, tensile strength and elongation at fracture increased with an increasing silica volume fraction up to $35 \%$, whereas the Young's modulus displayed small dependence on the silica content, and the resistance to tear increased continuously with filler volume fraction; however, no satisfactory results could be obtained at the edges of the prosthesis. ${ }^{16}$

In this clinical procedure, tulle, which is used in the theater for sewing on a beard or mustache, was used to increase the tear resistance of the margin of a facial prosthesis. Tulle is fabricated in various colors, ranges of elasticity and densities, and acts as a framework inside the silicone. The incorporation of the tulle into the margins of a silicone prosthesis results in margins that are more stable, more resistant to tearing, and less likely to deform during application or removal of adhesives, cosmetics, or cleaning agents. The purpose of this article is to introduce a new technique for improving the edge strength of silicone elastomeres used for the fabrication of facial prosthesis.

\section{CLINICAL REPORT}

A 43-year-old man with a resection of the right orbital and nasal area caused by basal cell carcinoma is presented (Figs. I and 2). After recovery from surgery, the patient was referred to the department of Maxillofacial Prosthetics, Istanbul University, for the fabrication of a facial prosthesis. The treatment plan was to fabricate a facial prosthesis, incorporating tulle, to reduce the 


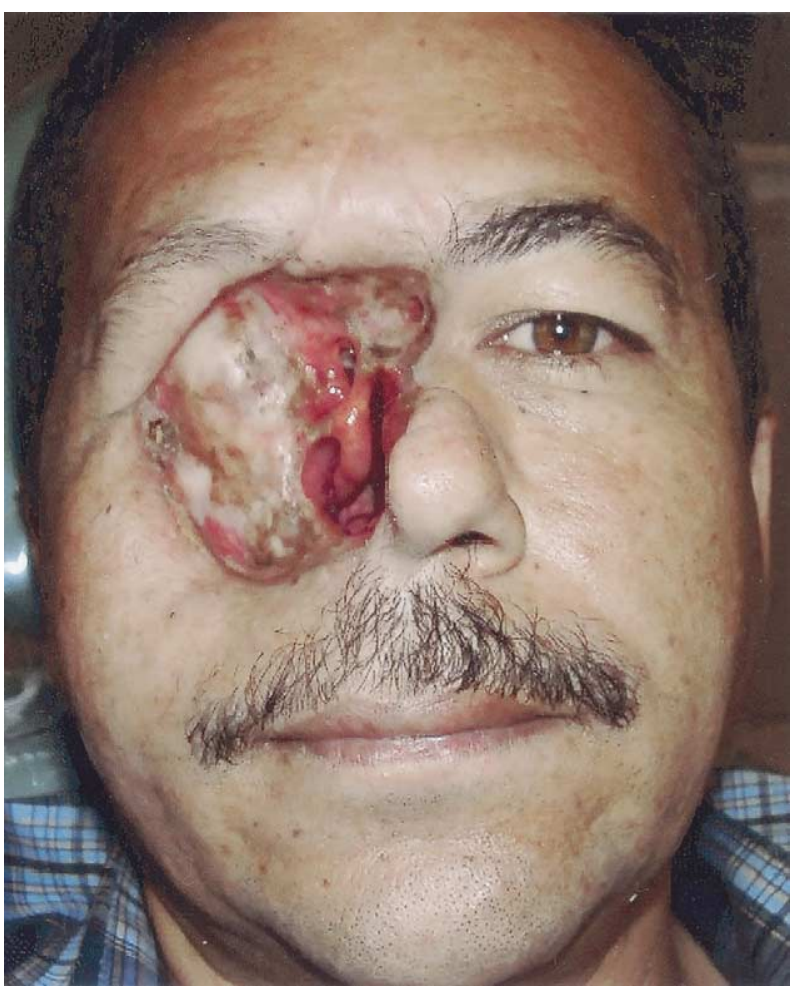

Fig. 1. Frontal view of right orbital-facial defect.

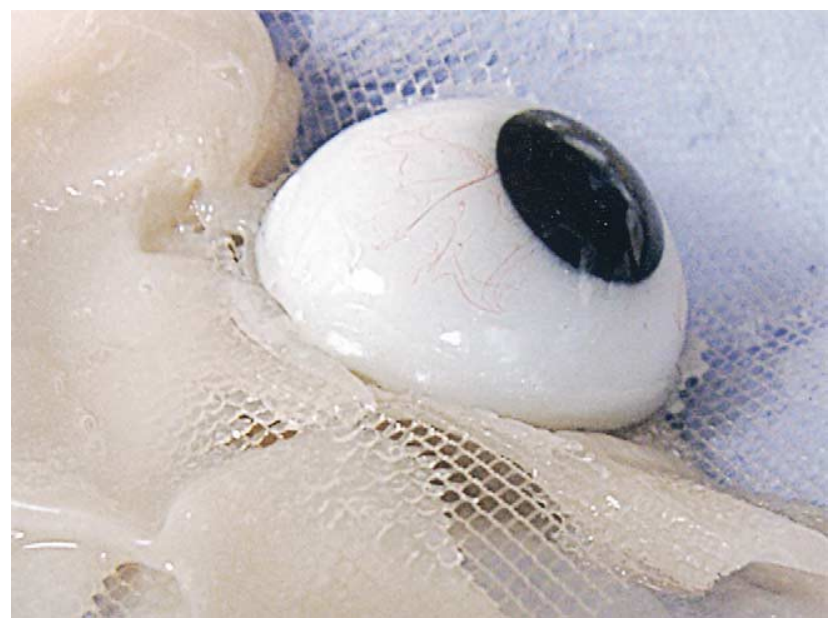

Fig. 3. Ocular prosthesis bonded to tulle with polymethylmetacrylate.

problem of marginal tearing. An impression of the patient's facial defect was made in irreversible hydrocolloid. (Alginate; Zhermack, S.p.A, Padua, Italy). A backing of plaster was used as a support for impression material. The impression was poured in type $\mathrm{V}$ dental stone (Die Keen; Bayer Corp, South Bend, Ind). The preliminary wax sculpture of the prosthesis was assessed on the patient. After the elimination of the wax in the

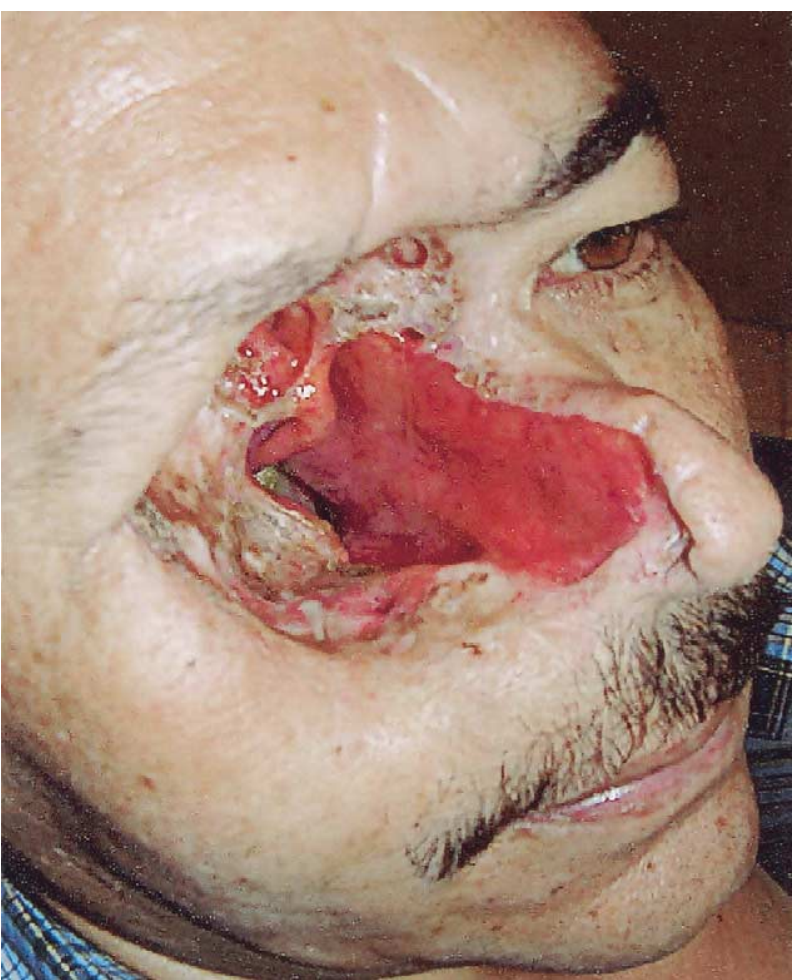

Fig. 2. Lateral view of right orbital-facial defect.

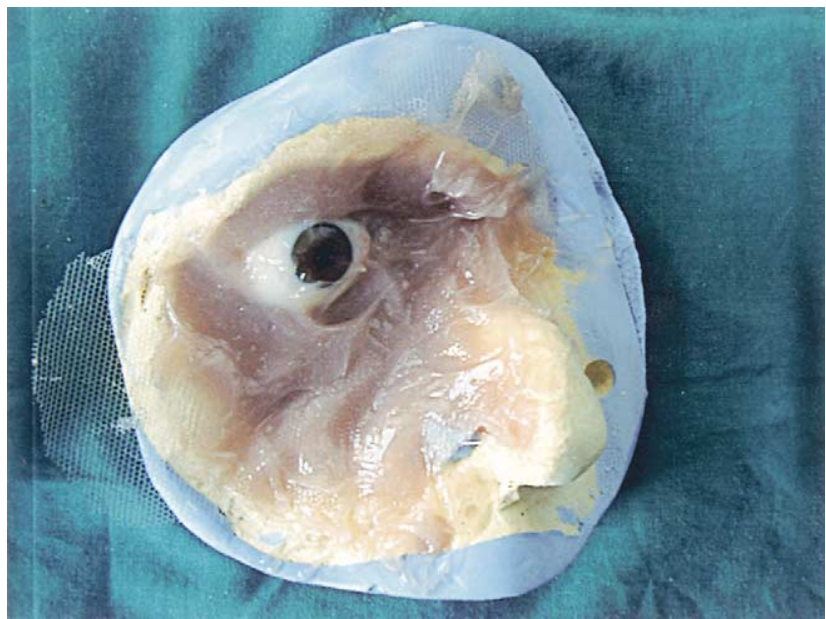

Fig. 4. Processed silicone.

stone mold, 1 layer of tulle (Kryolan Gmbh, Berlin, Germany) was prepared by cutting the tulle with scissors to a size slightly larger than the prosthesis to be fabricated. Then a hole similar in shape but smaller in dimensions than the ocular portion of the prosthesis was cut in the middle of the tulle. The tulle was bonded to the fixed ocular portion of the prosthesis using auto-polymerizing resin (Orthocryl Rapid resin, D-7530; Stratford- 


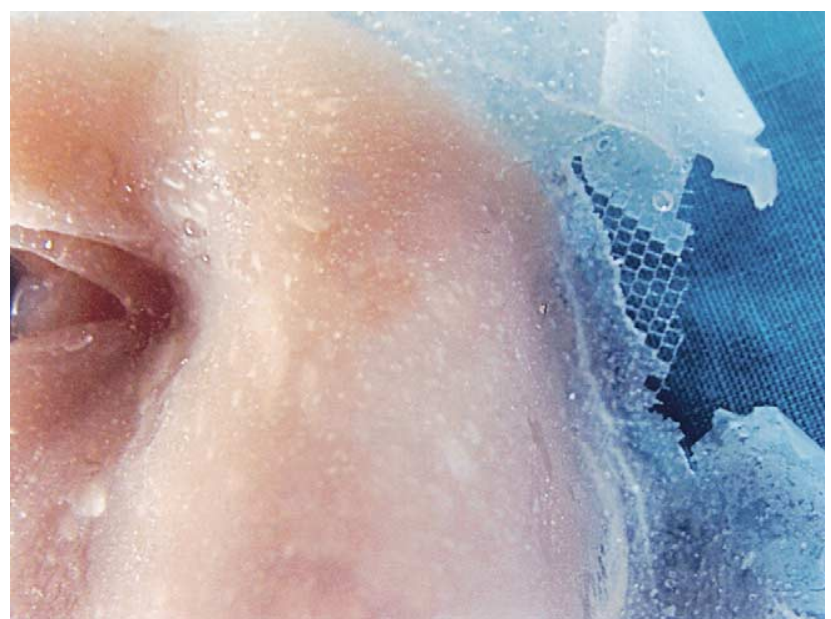

Fig. 5. Excess silicone flash ready for removal.

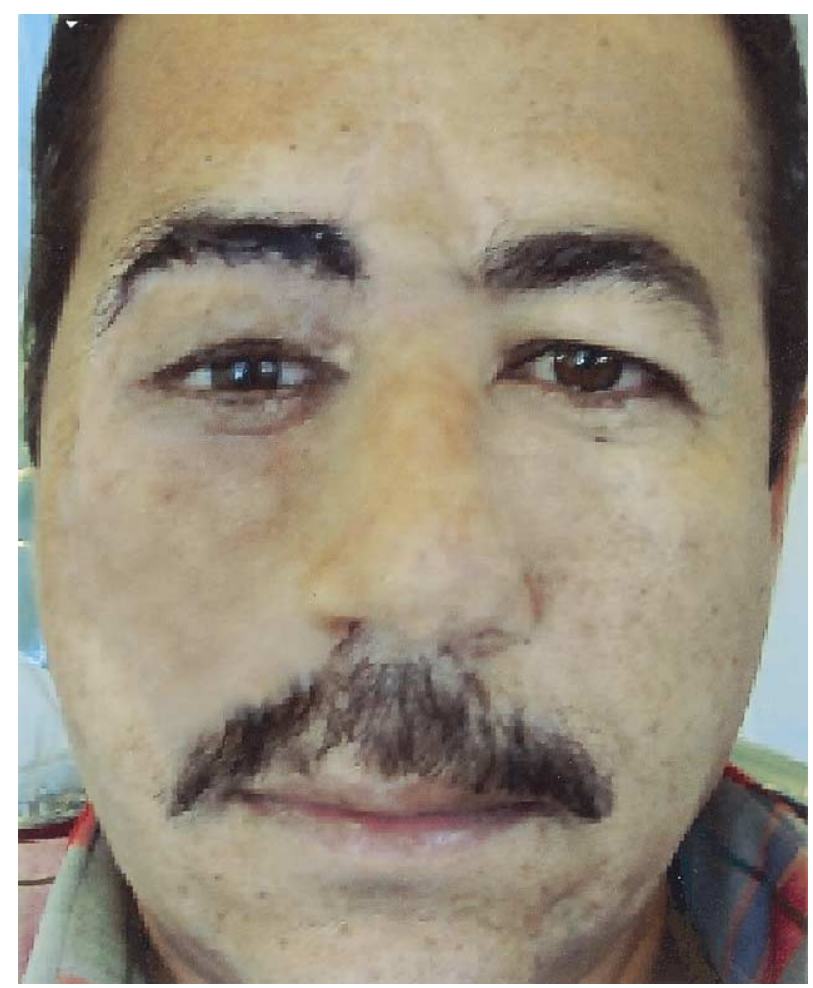

Fig. 7. Complete prosthesis.

Cookson, Pforzheim, Germany). As a result, the ocular portion was fixed to the borders of the tulle (Fig. 3). Room temperature vulcanizing (RTV) silicone elastomer (VST50F; Factor II Inc, Lakeside, Ariz) was packed and processed in the stone mold (Fig. 4). After the complete polymerization of silicone elastomer, the mold was opened, the excess silicone was trimmed, and the edges were smoothed with a trimming kit (Factor II Inc, Lakeside, Ariz) (Fig. 5). Extrinsic color was applied

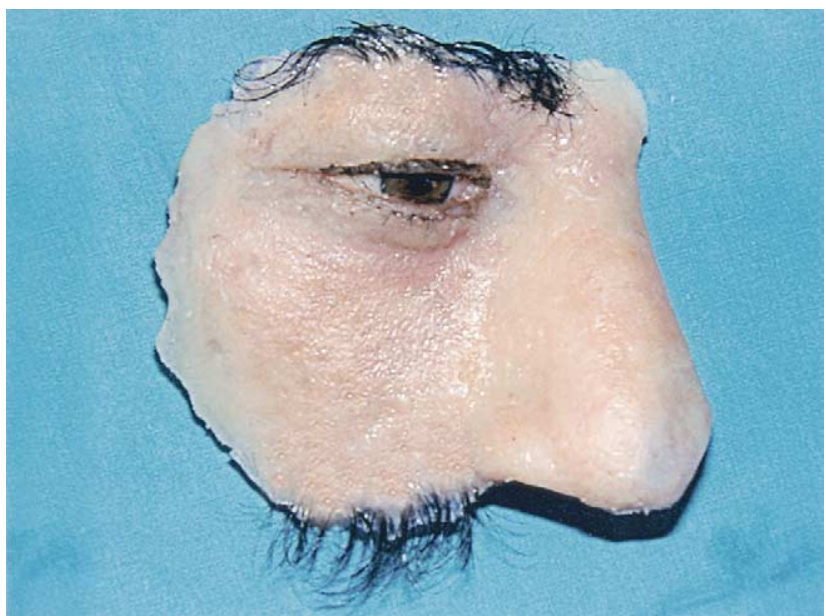

Fig. 6. Eye brows and eyelashes applied.

to the prosthesis to match the patient's skin tone. After the application of eyebrows and eyelashes, the prosthesis was placed on the patient (Figs. 6 and 7). Medical grade adhesive (Secure Adhesive; Factor II Inc, Lakeside, Ariz) was used for prosthesis retention, augmented by the anatomic undercuts. At the recall appointment of the first, third, and sixth month, it was observed that there was no tearing or deformation of the prosthesis' margins related to the application of adhesives and cleaning agents. With improved material edge strength, it was easier for the patient to apply or remove adhesives, cosmetics, and cleansers without damaging the margins of the prosthesis.

\section{SUMMARY}

This article described the treatment of a patient with a mid-facial defect. A facial prosthesis was fabricated with tulle to reduce the problem of tearing at the margins.

\section{REFERENCES}

1. Beumer J, Curtis TA, Maurinick MT. Maxillofacial rehabilitation: prosthodontic and surgical considerations. St. Louis: Ishiyaku EuroAmerica. Inc; 1996 p. 377-436.

2. McKinstry RE. Fundamentals of facial prosthetics. Clearwater: ABI Professional Publications; 1995 p. 1-9, 79-99.

3. Wolfaardt JF, Chandler HD, Smith BA. Mechanical properties of a new facial prosthetic material. J Prosthet Dent 1985;53:228-34.

4. Yu R, Koran A 3rd, Craig RG. Physical properties of a pigmented silicone maxillofacial material as a function of accelerated aging. J Dent Res 1980;59:1141-8.

5. Hulterstrom AK, Ruyter IE. Changes in appearance of silicone elastomers for maxillofacial prostheses as a result of aging. Int J Prosthodont 1999; 12:498-504.

6. Polyzois GL. Mechanical properties of 2 new addition-vulcanizing silicone prosthetic elastomers. Int J Prosthodont 1999;12:359-62.

7. Moore DJ, Glaser ZR, Tabacco MJ, Linebaugh MG. Evaluation of polymeric materials for maxillofacial prosthetics. J Prosthet Dent 1977;38:31926.

8. Lewis DH, Castleberry DJ. An assessment of recent advances in external maxillofacial materials. J Prosthet Dent 1980;43:426-32. 
9. Polyzois GL, Tarantili PA, Fangou MJ, Andreopoulos AG. Physical properties of a silicone prosthetic elastomer stored in simulated skin secretions. J Prosthet Dent 2000;83:572-7.

10. Andreopoulos AG, Evangelatou M. Evaluation of various reinforcements for maxillofacial silicone elastomeres. J Biomater Appl 1994;8:344-60.

11. Haug SP, Moore BK, Andres CJ. Color stability and colorant effect on maxillofacial elastomeres. Part II: weathering effect on physical properties. J Prosthet Dent 1999;81:423-30.

12. Mohite UH, Sandrik JL, Land MF, Byrne G. Environmental factors affecting mechanical properties of facial prosthetic elastomers. Int J Prosthodont 1994;7:479-86.

13. Udagama A. Urethane-lined silicone facial prosthesis. J Prosthet Dent 1987;58:351-4

14. Wang R, Collard SM, Lemon J. Adhesion of silicone to polyurethane in maxillofacial prosthesis. Int J Prosthodont 1994;7:43-9.

15. Andres CJ, Haug SP, Munoz CA. Effects of environmental factors on maxillofacial elastomers: Part I-Literature review. J Prosthet Dent 1992; 68:327-30.

16. Andreopoulos AG, Evangelatou M, Tarantili PA. Properties of maxillofacial silicone elastomers reinforced with silica powder. J Biomater Appl 1998;13:66-73.
17. Sweeney WT, Fischer TE, Castleberry DJ, Cowperthwaite GF. Evaluation of improved maxillofacial prosthetic materials. J Prosthet Dent 1972;27: 297-305.

Reprint requests to:

Dr Gulumser EvLIOGLu

Istanbul Universitesı Dış heKIMlı̌̆l FakÜltesı

Protetik Diş Tedavisı Ana Bılım Dalı-Çene Yüz Protezlerı Bılım Dalı

34390 ÇAPA ISTANBUL

TURKEY

FAX: 00902126310068

E-MAIL: bkyazgan@superonline.com

Copyright (C) 2003 by The Editorial Council of The Journal of Prosthetic Dentistry.

$0022-3913 / 2003 / \$ 30.00+0$

doi:10.1016/j.prosdent.2003.08.002

\section{New product news}

The January and July issues of the Journal carry information regarding new products of interest to prosthodontists. Product information should be sent 1 month prior to ad closing date to: Dr. Carol A. Lefebvre, Editor, The Journal of Prosthetic Dentistry, School of Dentistry, AD-1112, Medical College of Georgia, Augusta, GA 30912-1255. Product information may be accepted in whole or in part at the discretion of the Editor and is subject to editing. A black-and-white glossy photo may be submitted to accompany product information.

Information and products reported are based on information provided by the manufacturer. No endorsement is intended or implied by the Editorial Council of The Journal of Prosthetic Dentistry, the editor, or the publisher. 